\title{
EDITORIAL
}

\section{Asthma control: where do we fail?}

\author{
J.C. Kips, R.A. Pauwels
}

The present issue of the European Respiratory Journal publishes the results of the Asthma Insights and Reality in Europe (AIRE) study, a large scale telephone survey assessing the degree of asthma control as experienced by patients in Europe [1]. In line with other recent surveys [2, $3]$, this study indicates that at present the goals for longterm asthma management, as put forward in current guidelines [4] are clearly not being met. Half of the adults experienced daytime symptoms at least once a week, $30 \%$ reported asthma-related sleep disturbances at least once a week and $28 \%$ had required an unscheduled urgent care visit in the past 12 months. Uncontrolled asthma not only puts the patient at risk, but also has considerable economical implications, as this results in a substantial increase in asthma related healthcare utilization $[5,6]$. Therefore, it is important to understand the reasons for this overall lack of asthma control and from there on design strategies that efficiently improve this situation.

Several factors are likely to be involved. A striking observation in the AIRE study is that despite having symptoms, the majority of patients consider their asthma as being well controlled. It has been reported that some asthmatic patients poorly perceive symptoms and frequently underreport them to their physician [7]. As a consequence, patients might not always fully realize that they have the symptoms, without being actively asked. This seems important for the approach a physician should take in assessing asthma control. Symptoms should be actively inquired about, instead of waiting for them to be spontaneously mentioned. Instruments have been developed to do so relatively easily. It has recently been proposed that asking five simple but focused questions, measuring peak flow and recording the need for rescue medication is sufficient to properly evaluate the degree of asthma control [8]. The follow-up of asthma patients is probably insufficient, which is illustrated by the observation from the current study that $60 \%$ of children and $45 \%$ of adults had never had a lung function test. This highlights the continuing need for the education of physicians. Informing physicians about guidelines increases their knowledge, but does not automatically lead to behavioural changes. In order to be effective, education should focus on the practical implementation of the concepts introduced in the guidelines [9]. It has been shown that this can be done and that this carries significant long-term benefits for the asthma patient $[10,11]$.

Correspondence: J.C. Kips, Dept of Respiratory Diseases, Ghent University Hospital, De Pintelaan 185, B 9000 Ghent, Belgium. Fax: 3292402341.
However, other factors probably also contribute to the discrepancy between symptoms and perceived asthma control. Maybe patients expect asthma to cause certain disabilities, and therefore accept some degree of symptoms as being inevitable and adapt their lifestyle accordingly. This calls for renewed efforts in disseminating the key points from the current guidelines, underlying that asthma should not inhibit (near) normal physical activities, provided it is properly treated.

The absence of proper treatment is another key finding in the current survey. The majority of patients used $\beta_{2^{-}}$ agonists as required, but even in the group of patients with severe symptoms, only $25 \%$ used inhaled steroids. From this study, it cannot be deduced whether the low use of steroids is due to insufficient prescription or unwillingness from the patient to use the prescribed compounds. Data from a similarly designed Canadian study indicate that the majority of patients do not understand the rationale for using inhaled steroids. Most of them have significant fears concerning their side effects [12]. In addition, the cost of steroids as well as the resentment of having to use regular medication is likely to further diminish patient adherence to inhaled steroids $[13,14]$. These various factors can lead to a situation where patients prefer symptoms to treatment with steroids. This might again call upon a change in the patient approach. There is ample evidence that inhaled steroids, even at low doses are cost-effective at improving symptoms, lung function and at reducing mortality $[15$, 16]. In addition, even when used over a long time period, low to moderate doses of inhaled steroids appear to be safe [17]. Reiterating this information both towards physicians and patients would therefore, seem very appropriate. Studies based on questionnaires as well as on general practice records indicate that physicians insufficiently prescribe maintenance treatment $[18,19]$. However, specific education programs increase both the prescription rate of and adherence to steroids, improving the overall degree of asthma control [9-11, 20]. This message can be strengthened by a broad application of the "add-on" approach, combining 2 controller medications as opposed to installing high doses of inhaled steroids [21-23].

Finally, the validity of the gold standard, used to define asthma control in the patients needs considering. The Asthma Insights and Reality in Europe study shows that compared to the goals set by current guidelines, patients are insufficiently controlled. These goals have been reached by consensus. The possibility exists that they might be over-ambitious for use in daily practice. Although, current treatment is effective in reducing symptoms in a majority of patients, it does not control asthma fully. Even 
the combination of inhaled steroids with long-acting inhaled $\beta_{2}$-agonists at routinely advocated doses in mild to moderate persistent asthma does not succeed in reducing the percentage of days with no asthma symptoms to below $50 \%$ [23-25]. In patients with more severe disease, this result is even unachievable without inducing treatment related side effects. This therefore, means that it might be more realistic to adapt the goals of asthma treatment to the efficacy of currently available treatment regimens and the severity of the disease. In addition, it remains to be proven whether adapting treatment intensity to maintain full asthma control, if at all possible, will improve the long-term outcome of asthma, avoid side effects and reduce healthcare utilization. Only then will it be known whether in the end, the Asthma Insights and Reality in Europe study proves that the patient is right or wrong in minimizing treatment and accepting some degree of symptoms.

\section{References}

1. Rabe KF, Vermeire PA, Soriano JB, Maier WC. Clinical management of asthma in 1999: the Asthma Insights and Reality in Europe (AIRE) study. Eur Respir J 2000.

2. Joyce DP, Mcivor RA. Use of inhaled medications and urgent care services. Study of Canadian asthma patients. Can Fam Physician 1999; 45: 1707-1713.

3. Rickard KA, Stempel DA. Asthma survey demonstrates that the goals of the NHLBI have not been accomplished. J Allergy Clin Immunol 1999; 103: s171.

4. Global initiative for asthma. Global strategy for asthma management and prevention. Washington, D.C. National Heart, Lung, and Blood Institutes, 1995 (Publication no. 95-3659).

5. Barnes PJ, Jonsson B, Klim JB. The costs of asthma. Eur Respir J 1996; 9: 636-642.

6. Vollmer WM, Markson LE, O'Connor E, et al. Association of asthma control with health care utilization and quality of life. Am J Respir Crit Care Med 1999; 160: 1647-1652.

7. van Schayck CP, van Der Heijden FM, van Den Boom G, Tirimanna PR, van Herwaarden CL. Underdiagnosis of asthma: is the doctor or the patient to blame? The DIMCA project. Thorax 2000; 55: 562-565.

8. Juniper EF, O'Byrne PM, Guyatt GH, Ferrie PJ, King DR. Development and validation of a questionnaire to measure asthma control. Eur Respir J 1999; 14: 902-907.

9. Clark NM, Gong M. Measurement of chronic disease by practitioners and patients: are we teaching the wrong things? BMJ 2000; 320: 572-575.

10. Veninga CC, Lagerlov $\mathrm{P}$, Wahlstrom $\mathrm{R}$, et al. Evaluating an educational intervention to improve the treatment of asthma in four European countries. Drug Education Group. Am J Respir Crit Care Med 1999; 160: 12541262.
11. Clark NM, Gong M, Schork MA, et al. Long-term effects of asthma education for physicians on patient satisfaction and use of health services. Eur Respir J 2000; 16: 15-21.

12. Boulet LP. Perception of the role and potential side effects of inhaled corticosteroids among asthmatic patients. Chest 1998; 113: 587-592.

13. Adams S, Pill R, Jones A. Medication, chronic illness and identity: the perspective of people with asthma. Soc Sci Med 1997; 45: 189-201.

14. Gottlieb DJ, Beiser AS, O'Connor GT. Poverty, race, and medication use are correlates of asthma hospitalization rates. Chest 1995; 108: 28-35.

15. Rutten-van Mölken MPMH, Van Doorslaer EKA, Jansen MCC, van-Essen-Zandvliet EE, Rutten FFH. Cost effectiveness of inhaled corticosteroid plus bronchodilator therapy versus bronchodilator monotherapy in children with asthma. Pharmacoeconomics 1993; 4: 257-270.

16. Suissa S, Ernst P, Benayoun S, Baltzan M, Cai B. Lowdose inhaled corticosteroids and the prevention of death from asthma. N Engl J Med 2000; 343: 332-336.

17. Agertoft L, Pedersen S. Effect of long-term treatment with inhaled budesonide on adult height in children with asthma. New Engl J Med 2000; 343: 1064-1069.

18. Bousquet J, Knani J, Henry C, et al. Undertreatment in a nonselected population of adult patients with asthma. $J$ Allergy Clin Immunol 1996; 98: 514-521.

19. Walsh LJ, Wong CA, Cooper S, Guhan AR, Pringle M, Tattersfield AE. Morbidity from asthma in relation to regular treatment: a community based study. Thorax 1999; 54: 296-300.

20. Gallefoss F, Bakke PS. How does patient education and self-management among asthmatics and patients with chronic obstructive pulmonary disease affect medication? Am J Respir Crit Care Med 1999; 160: 2000-2005.

21. Greening AP, Ind PW, Northfield M, Shaw G. Added salmeterol versus higher-dose corticosteroid in asthma patients with symptoms on existing inhaled corticosteroid. Lancet 1994; 344: 219-224.

22. Woolcock AJ, Lundback B, Ringdal N, Jacques LA. Comparison of addition of salmeterol to inhaled steroids with doubling of the dose of inhaled steroids. Am J Respir Crit Care Med 1996; 153: 1481-1488.

23. Pauwels RA, Löfdahl C-G, Postma DS, et al. Effect of inhaled formoterol and budesonide on exacerbations of asthma. $N$ Engl J Med 19997; 337: 1405-1411.

24. Kavuru M, Melamed J, Gross G, et al. Salmeterol and fluticasone propionate combined in a new powder inhalation device for the treatment of asthma: a randomized, double-blind, placebo-controlled trial. J Allergy Clin Immunol 2000; 105: 1108-1116.

25. Shapiro G, Lumry W, Wolfe J, et al. Combined salmeterol 50 microg and fluticasone propionate 250 microg in the diskus device for the treatment of asthma. Am J Respir Crit Care Med 2000; 161: 527-534. 